\title{
A CONTRIBUIÇÃO DOS AMBIENTES VIRTUAIS COLABORATIVOS PARA CIDADES INOVADORAS SUSTENTÁVEIS
}

\section{THE CONTRIBUTION OF VIRTUAL COLLABORATIVE ENVIRONMENTS FOR SUSTAINABLE INNOVATIVE CITIES}

\author{
Marisa Carvalho ${ }^{1}$, Dra. \\ Helena Cirimbelli Bittencourt ${ }^{2}$ \\ Caio Fraile Gonçalves ${ }^{3}$ \\ (1) Universidade Federal de Santa Catarina \\ e-mail:marisa19@gmail.com \\ (2) Universidade Federal de Santa Catarina \\ e-mail:helenacirimbelli@gmail.com \\ (3) Universidade Federal de Santa Catarina \\ e-mail: caiofraile@hotmail.com
}

Palavras-chave: Ambientes Virtuais Colaborativos; Cidades Inovadoras Sustentáveis; Web 2.0

As cidades enfrentam desafios dos atuais sistemas urbanos gerados pelo modo de vida urbano. Discute-se a contribuição dos Ambientes Virtuais Colaborativos na visualização das melhores práticas das Cidades Inovadoras Sustentáveis. Apresentando os processos estruturantes das Comunidades Virtuais de Prática-VCoPs, comunicação e colaboração, com base no modelo crowdsourcing da Web 2.0

Key-words: Collaborative Virtual Environments; Sustainable Innovative Cities; Web 2.0

Cities face challenges from the current urban systems generated by the urban way of life. It is discussed the contribution of the Collaborative Virtual Environments on the visualization of the best practices to Innovative Sustainable Cities. Introducing the structuring processes of Virtual Communities of Practice-VCoPs, communication and collaboration, based on crowdsourcing model of Web 2.0

\section{Introdução}

O modo de vida urbano é parte do problema e parte da solução no futuro das cidades no que se refere à qualidade de vida. As cidades têm características culturais e arquitetônicas únicas, uma forte capacidade de inclusão social e excelentes oportunidades de desenvolvimento econômico. São centros de conhecimento, fontes de crescimento e inovação. Mas ao mesmo 
$16^{\circ}$ Ergodesign - Congresso Internacional de Ergonomia e Usabilidade de Interfaces Humano Tecnológica: Produto, Informações Ambientes Construídos e Transporte

$16^{\circ}$ USIHC - Congresso Internacional de Ergonomia e Usabilidade de Interfaces Humano Computador

CINAHPA | 2017 - Congresso Internacional de Ambientes Hipermídia para Aprendizagem.

tempo, debatem-se com problemas demográficos, desigualdade e exclusão social de grupos populacionais específicos, falta de alojamento adequado a preços acessíveis e problemas ambientais [LEIPZIG CHARTER, 2007].

A crescente concentração da população nas cidades, conforme a Carta de Leipzig das Cidades Europeias Sustentáveis [2007], para o desenvolvimento urbano e coesão territorial dos estados, introduz uma nova dimensão aos sistemas urbanos e as políticas públicas desenvolvidas destacando a importância do fortalecimento do papel das cidades e da troca de melhores práticas entre os agentes urbanos. A colaboração entre eles favorece o aparecimento das soluções urbanas aos desafios sociais e demográficos, gerados pelos atuais sistemas urbanos e na qual as cidades enfrentam problemas para seguir os propósitos e estudos do desenvolvimento urbano sustentável difundidos, por exemplo, por governantes da União Européia e/ou pelas comunidades de prática formadas na Internet.

A evolução das aplicações Web 1.0- conteúdos estáticos a Web 2.0- conteúdos com interações dinâmicas têm facilitado reunir indivíduos com interesses comuns na aprendizagem situada e coletiva e assim, interagem e formam as Comunidades de Prática- CoPs [Lave e Wenger, 1998] para estabelecer a criação, aquisição, armazenamento e o compartilhamento do conhecimento, ou seja, as melhores práticas. Que em soluções urbanas, surgem por meio da interação entre os agentes urbanos como 1.comunidades: sociedade civil, institutos, grupos de pesquisa e organizações não governamentais e 2.gestores: públicos, nos três níveis de governo, e privados, do setor empresarial, que reunidos em um ambiente virtual favorecem a aprendizagem colaborativa.

A Web 2.0 envolve novas formas de aprendizagem e de assimilação das informações
[Saad, 2003] facilitando o processo de formação das CoPs. Ao ingressar no ambiente virtual, as CoPs passam a ser consideradas, de acordo com Terra e Gordon [2002] e von Wartburg et al [2005], como Virtual Communities of Practice VCoPs caracterizadas por interações virtuais, pois baseiam-se primordialmente em espaços virtuais. Anthony et al [2009] discorre sobre a aprendizagem colaborativa, pois consideram que as VCoPs reunidas em um ambiente virtual proporcionam um trabalho com iniciativas conjuntas, de forma colaborativa, propondo representações e modelos de suas ideias, ou seja, soluções para problemas comuns.

A colaboração se dá por meio de ambientes virtuais disponíveis na Internet, como os portais e as redes sociais, com suas formas de comunicação específicas da Web 2.0, ou seja, por meio da oferta de dispositivos tecnológicos que permitem a comunicação entre os agentes urbanos das VCoPs. Esta surge como fortalecimento das interações entre os agentes urbanos e por conseguinte entre as cidades, contribuindo para a transparência nas demandas do serviço público, gestão administrativa e orçamento participativo. Assim, a sociedade tem condições de participar e colaborar efetivamente na administração pública, seja na elaboração de propostas e de programas do governo, seja exercendo o controle social dos recursos públicos para melhoria do desenvolvimento urbano das cidades.

As VCoPs distribuídas pela Internet têm como objetivo de conhecer e melhorar as cidades, e apresentam soluções urbanas ainda pouco exploradas, como os desenvolvimentos de produtos, negócios, projetos e movimentos urbanos que surgem da aprendizagem colaborativa, sugerido por Howe [2008] de crowdsourcing que mostram com clareza a não dependência de instituições centralizadas para resolver problemas urbanos complexos com intuito de apoio a tomada de decisão no âmbito dos agentes urbanos. O exemplo de 


\section{$16^{\circ}$}

\section{ERGODESIGN USIHC CINAHPA}

crowdsourcing que propicia a experiência de cidadania na Web 2.0 deu-se o nome de Webcidadania. Termo usado para explicar o fenômeno da utilização da Web 2.0 para promover o engajamento do cidadão em uma ação de interesse público. A co-criação surge como um processo para engajar pessoas e proposição de projetos, programas e políticas públicas. No Brasil, existem muitos exemplos de crowdsourcing tais como Cidade Democrática http://www.cidadedemocratica.org.br/ e Vote na Web São Paulo http://saopaulo.votenaweb.com.br/, são ambientes virtuais de colaboração e de participação política que tem como objetivo estimular o engajamento cívico, aproximar os cidadãos entre si, de seus governos e da iniciativa privada para a construção de uma sociedade cada vez melhor, e consequentemente apresentando soluções urbanas inovadoras para cidades.

Outra questão é a descentralização que está no conceito de crowdsourcing que é a obtenção de ideias, geração de conteúdos ou serviços a partir das colaborações vindas das VCoPs. Howe [2006, 2008] explica que a colaboração em massa, formada em grande parte por indivíduos amadores, cujas contribuições muitas vezes não estão dentro do escopo da sua profissão, pois a força de trabalho está quase que totalmente fora da organização. Para Tapscott e Willians [2007] o termo é usado para designar um modelo de criação coletiva e em massa que utiliza a inteligência e o conhecimento coletivo de voluntários, amadores ou não, dispersos nos ambientes virtuais para desenvolver novas tecnologias ou solucionar problemas.

Pode-se de maneira geral afirmar que os ambientes virtuais são compostos por VCoPs e tem como função básica agir como centro de geração e socialização de conhecimentos [Kunzmann, 2009]. Na construção de um ambiente virtual leva-se em consideração que a aprendizagem acontece, por meio da $16^{\circ}$ Ergodesign - Congresso Internacional de Ergonomia e Usabilidade de Interfaces Humano Tecnológica: Produto, Informações Ambientes Construídos e Transporte

$16^{\circ}$ USIHC - Congresso Internacional de Ergonomia e Usabilidade de Interfaces Humano Computador

CINAHPA | 2017 - Congresso Internacional de Ambientes Hipermídia para Aprendizagem.

colaboração do conhecimento, na cultura baseada em conhecimentos compartilhados entre os agentes das VCoPs. Uma característica relevante dos ambientes virtuais na Web 2.0 é o fato de serem sistemas dinâmicos, ou seja, os cenários se modificam em tempo real à medida que os agentes vão interagindo com o ambiente, afirmam Kirner e Tori, [2004]. Saad [2003] destaca o princípio relevante para o ambiente virtual: o princípio da colaboração que é encontrado no conceito da Web 2.0 e utilizado em diferentes áreas como educação, economia, e-Gov e cidades.

As abordagens das Cidades Inovadoras, Cidades Sustentáveis, Cidades Inteligentes e do Desenvolvimento Urbano baseado no Conhecimento- DUBC buscam soluções urbanas dentre as quais Carrillo [2006] cita como importantes a criação de novas opções de planejamento urbano, incentivos à inovação aberta, desenvolvimento econômico, social e sustentável. A diferença entre as abordagens das cidades reside basicamente nos elementos usados como alicerces na produção de soluções urbanas para os problemas identificados no sistema urbano atual. Então nesta conjuntura é possível entender os tipos de cidades por meio de suas principais características: inteligência, inovação e sustentabilidade. Utilizou-se para isso a integração dos conceitos de cidades, denominando Cidades Inovadoras Sustentáveis visando levantar as futuras soluções urbanas a partir das VCoPs reunidas em um Ambiente Virtual Colaborativo.

$\mathrm{O}$ ponto de encontro na Internet que permite a interação entre as VCoPs é definido por Benford [apud Gouveia, 2000] como Ambiente Virtual Colaborativo, do inglês Collaborative Virtual Environments- CVE. A contribuição dos Ambientes Virtuais Colaborativos para Cidades Inovadoras Sustentáveis consiste em estabelecer as interações e o compartilhamento do conhecimento novo, por conseguinte, das melhores práticas entre os agentes urbanos que 
$16^{\circ}$ Ergodesign - Congresso Internacional de Ergonomia e Usabilidade de Interfaces Humano Tecnológica: Produto, Informações Ambientes Construídos e Transporte

$16^{\circ}$ USIHC - Congresso Internacional de Ergonomia e Usabilidade de Interfaces Humano Computador

CINAHPA | 2017 - Congresso Internacional de Ambientes Hipermídia para Aprendizagem.

formam as VCoPs. Pode-se apresentar e visualizar, por exemplo, a elaboração de políticas públicas, a divulgação de estudos urbanos, desenvolvimento de projetos e programas sobre os eixos do sistema urbano mais relevantes a nível local e global, para assim favorecer o apoio a tomada de decisão por parte dos agentes urbanos.

Para isso propõe-se os Ambientes Virtuais Colaborativos que consistem em um sistema de gestão composto por um 1.repositório, ou seja, big data que armazena, transfere, visualiza e compartilha o conhecimento pelos agentes urbanos; pelas 2.formas de comunicação que estão disponíveis na Web 2.0 possibilitando o ambiente virtual crescer de forma multi e interdisciplinar com objetivo de promover a colaboração; e pelo 3.modelo de crowdsourcing para o desenvolvimento urbano e sua futura implantação concreta prevê soluções urbanas formuladas pelas VCoPs, quer sejam instituições, indivíduos ou organizações. Portanto, os Ambientes Virtuais Colaborativos para as Cidades Inovadoras Sustentáveis surgem como um instrumento de apoio à tomada de decisão aos agentes urbanos, quanto a proposição e seleção das futuras soluções urbanas apresentadas pelas VCoPs, como também a alocação de recursos humanos e financeiros para a gestão dos diferentes eixos dos sistemas urbanos pertinentes as demandas apresentadas.

\section{Cidades Inovadoras Sustentáveis}

O termo cidade pode referir-se as percepções de um modo de vida urbano e as características culturais ou sociais específicas, bem como as atividades e trocas econômicas nas chamadas comunidades. Vistas como uma unidade administrativa ou a uma determinada densidade populacional, do mesmo modo, corresponde às realidades físicas ou socioeconômicas que foram abordadas através de uma definição morfológica ou funcional formando sistemas urbanos complexos. Define-se ainda, quer pelas aglomerações urbanas em termos gerais quer pelas unidades administrativas que as governam [Comissão Europeia, 2011]. Pode ainda ser definida como comunidades (bairros ou regiões) que promovem sistematicamente $o$ empoderamento e bem-estar de todos os seus participantes, proativamente e sustentavelmente. São capazes de transformar o espaço físicohabitat em um espaço de convivências cada vez melhor para morar, trabalhar, estudar e ter lazer.

O processo de comunicação colaborativa que se dá entre os agentes urbanos das $\mathrm{VCoPs}$, possibilita a criação de soluções urbanas para Cidades Inovadoras Sustentáveis. O que caracteriza as Cidades Inovadoras Sustentáveis, pode-se dizer que é 1 .a oferta dos recursos tecnológicos da Web 2.0 como um conjunto emergente de aplicativos interativos, com contextos ricos e fáceis de usar entre as VCoPs [Carvalho, 2013]; 2.são habitadas por pessoas com grande capacidade de aprender, adaptar-se e inovar [Florida, 2002,2005]; 3.e que utilizam as dimensões humana, tecnológica e institucional para, sistematicamente, promover o desenvolvimento sustentável, melhoria dos serviços públicos e qualidade de vida [KOMNINOS 2002;2006].

A abordagem da inovação aberta consiste em que as comunidades participem e colaborem, por meio de um ambiente virtual no envio de ideias para problemas locais e globais. As VCoPs junto com as organizações se engajam neste movimento buscando co-criar produtos e serviços futuros e assim, resultar em novos conhecimentos. Pode-se afirmar que inovação aberta é um modelo no qual as empresas estão adotando cada vez mais em resposta a um mundo caracterizado pelas entidades de negócios globais e pelo compartilhamento aberto de informações. Chesbrough [2012] acredita na permeabilidade que as empresas passam a ter em relação aos conhecimentos externos a elas para gerar inovação a partir do reconhecimento de que o mundo agora é 


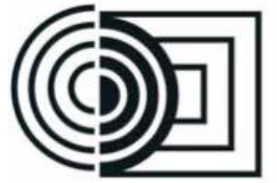

abundante em conhecimento.

Chesbrough [2003] defende que o processo de inovação aberta é colaborativo, buscando acessar conhecimento a partir de diversos agentes internos e externos. E que a gestão das ideias internas e externas, a manutenção do capital intelectual, o compartilhamento do conhecimento, a intermediação do conhecimento e a conectividade, iniciam-se novas interações sociais e desencadeiam uma força democrática e descentralizada de participação na sociedade, para além das fronteiras institucionais.

A concepção inicial da presente proposta, Cidades Inovadoras Sustentáveis, incluiu uma análise crítica dos modelos de cidades já existentes, tais como: cidades inteligentes, cidades inovadoras e cidades sustentáveis. Visa a integração dos principais termos a fim de potencializar e de transformar as comunidades locais em agentes urbanos ativos. Favorecendo uma comunidade economicamente forte, ecologicamente sustentável e socialmente mais justa, que por meio da construção de um ambiente virtual promova a colaboração e a visualização das ações propostas por vários agentes urbanos. A integração dos tipos de cidades partiu da observação das suas características principais, portanto, se faz necessário entender as definições que abarcam a inter-relação dos termos empregados nas seguintes cidades: inteligente, inovadora e sustentável, apresentados a seguir.

\subsection{Tipos Cidades e Características Principais}

Segundo Hall [2000], a Cidade Inteligente é aquela que monitora e integra as condições de operações de todas as infraestruturas críticas da cidade, atuando de forma preventiva para a continuidade de suas atividades fundamentais. $\mathrm{O}$ que caracteriza uma Cidade Inteligente, pode-se dizer que é a combinação de infraestrutura e serviços baseados em Tecnologias de Informação e Comunicação-TICs. Na exploração destes recursos de maneira inovadora $16^{\circ}$ Ergodesign - Congresso Internacional de Ergonomia e Usabilidade de Interfaces Humano Tecnológica: Produto, Informações Ambientes Construídos e Transporte

$16^{\circ}$ USIHC - Congresso Internacional de Ergonomia e Usabilidade de Interfaces Humano Computador

CINAHPA | 2017 - Congresso Internacional de Ambientes Hipermídia para Aprendizagem. e colaborativa por meio da Web 2.0 para o gerenciamento da complexidade das cidades otimizando certos aspectos da vida urbana. $\mathrm{O}$ uso das tecnologias como um suporte para facilitar a análise de informações, que se encontra como elemento central, visto que pode ser incorporada em todas as decisões de planejamento e gestão urbana de forma a alcançar uma prestação de serviços mais eficiente e na melhoria da qualidade de vida das pessoas [STEVENTON e WRIGHT, 2009; KANTER e LITOW, 2009; TOPPETA, 2010].

Cidade Sustentável consiste na sinergia entre os avanços científico-tecnológico, sociocultural e institucional, que harmonizem os processos e impactos do desenvolvimento em nível local, tornando-o sustentável. Tendo como objetivo estimular a participação dos cidadãos como forma de contribuir para a melhoria da qualidade de vida de cada região, aproveitando a troca de informações e experiências em níveis local e global. É uma cidade ambientalmente equilibrada, onde não encontra lugar o crescimento desordenado que gere efeitos negativos ao meio ambiente, o uso inadequado dos imóveis, a proximidade de usos incompatíveis, a poluição e a degradação ambiental [Guimaraens, 2010].

Resume-se por Cidades Sustentáveis como compactas- densas, vivas e diversificadas, afirmam Souza e Awad [2012]. Uma Cidade Inovadora é quando os investimentos em seu capital humano, social e tradicional, em modernas infraestruturas de comunicação, alimentam um crescimento econômico sustentável e uma elevada qualidade de vida, com um prudente gerenciamento dos recursos naturais, através de uma governança participativa [Caragliu et al, 2009]. A inovação se manifesta quando a cidade promove o desenvolvimento econômico com justiça social e sustentabilidade ambiental. Adota e desenvolve tecnologias apropriadas para sua realidade local e usa processos de inovação e governança que ajudam a construir uma comunidade alinhada 
$16^{\circ}$ Ergodesign - Congresso Internacional de Ergonomia e Usabilidade de Interfaces Humano Tecnológica: Produto, Informações Ambientes Construídos e Transporte

$16^{\circ}$ USIHC - Congresso Internacional de Ergonomia e Usabilidade de Interfaces Humano Computador

CINAHPA | 2017 - Congresso Internacional de Ambientes Hipermídia para Aprendizagem.

com a cultura, os valores e os modos de vida urbano.

Uma cidade é inovadora e sustentável quando os recursos tecnológicos são utilizados no aprimoramento da gestão urbana, na relação com as demais partes interessadas e na criação de valor para a comunidade. E ajudam a construir uma comunidade alinhada com a cultura, os valores, o estilo de vida de seus residentes e na volição de promover os valores novos ou existentes. Pode-se então afirmar, que a essência das Cidades Inovadoras Sustentáveis são as comunidades que constroem os habitats como um ecossistema de forma prospectiva $\mathrm{e}$ alinhada quanto ao desenvolvimento social, econômico e tecnológico com foco no urbano, assegurando que os habitats se tornem inteligentes, inovadores e sustentáveis. Seu objetivo maior é co-criar os habitats para estimular a transformação dos espaços urbanos na promoção da qualidade de vida e de bemestar. Em uma dinâmica de sinergia com os cenários de futuro desejáveis de forma compartilhada inspirando os gestores urbanos na tomada de decisão e apontando oportunidades de inovação aberta.

\section{Ambiente Virtual Colaborativo}

Define-se ambiente virtual como uma tecnologia computacional que possui uma interface digital, mediadora entre o usuário, o sistema computacional e o suporte tecnológico. $\mathrm{O}$ objetivo dessa tecnologia é recriar ao máximo a sensação de realidade para o usuário, levando-o a adotar essa interação como uma de suas realidades temporais. Para isso, a interação é realizada em tempo real, com o uso de técnicas e de equipamentos computacionais que ajudem na ampliação do sentimento de presença do usuário por meio das interfaces digitais [WEXELBLAT, 1993; VALÉRIO et al, 2002; RHEINGOLD, 1998, 1999].

Para que um ambiente virtual seja considerado um Ambiente Virtual Colaborativo, Benford et al [1995] apresenta duas condições: a existência de um acesso simultâneo a um espaço virtual e o suporte explícito das necessidades daqueles que pretendem trabalhar em conjunto, ou seja, o sistema deve suportar as necessidades dos usuários que pretendam trabalhar em conjunto dentro do espaço virtual partilhado onde interagem entre si e com os recursos de informação disponíveis. Gouveia [2000] concorda com autores e acrescenta outras características de um Ambiente Virtual Colaborativo que são: permitir o acesso simultâneo de vários usuários ao sistema; permitir a sua interação; fornecer recursos de comunicação; e suportar as necessidades de comunicação e interação do usuário.

A interação favorece o desenvolvimento de ambientes virtuais permitindo a formação de comunidades virtuais que se envolvem, interagem e sintonizam as relações uns com os outros e com o mundo em conformidade ao que estão aprendendo, afirmam Lave e Wenger [1998]. Ao longo do tempo, isso resulta em práticas de aprendizagem coletiva que refletem tanto no exercício das organizações como nas relações de atendimento social. Essas práticas são a propriedade de um tipo de comunidade criada ao longo do tempo pela busca sustentada de uma organização comum. Segundo Pallof e Pratt [2007], interação e colaboração são fatores críticos no processo de desenvolvimento das VCoPs, sem estes conceitos não haveria comunidade. E a inclusão de práticas colaborativas aumenta a comunicação e a interação. Na colaboração o processo, produto ou evento é dinâmico, existindo uma interdependência entre os agentes da comunidade cujo objetivo é chegar a um novo conhecimento [SPYER, 2007].

Conforme Wenger, Mcdermott e Snyder [2002], um Ambiente Virtual Colaborativo inspira os participantes a contribuir, participar, incentivaos no aprendizado e dá sentido a suas ações. Portanto, o ambiente é o que define a identidade da comunidade e seu lugar no mundo virtual. 
$16^{\circ}$ Ergodesign - Congresso Internacional de Ergonomia e Usabilidade de Interfaces Humano Tecnológica: Produto, Informações Ambientes Construídos e Transporte

$16^{\circ}$ USIHC - Congresso Internacional de Ergonomia e Usabilidade de Interfaces Humano Computador

CINAHPA | 2017 - Congresso Internacional de Ambientes Hipermídia para Aprendizagem.

Saad [2003] destaca o princípio relevante para o ambiente virtual: o princípio da colaboração que é encontrado no conceito da Web 2.0 e utilizado em diferentes áreas como educação, economia, e-Gov, cidades, entre outras. Para Balloni e Targowski [2010] a evolução da $\mathrm{Web}$ denominada como Web 1.0 popularizou a Rede e se caracteriza com websites estáticos. Web $2.0 \mathrm{se}$ refere como um resultado de aperfeiçoamentos tecnológicos, como a banda larga, os navegadores melhorados e a ascensão de plataformas com diversas aplicações para gerar a colaboração. Tem sido geralmente considerada como a Web Social, ou seja, aproveitamento da inteligência coletiva e a gestão de bases de dados, baseada na participação dos agentes, emergindo experiências que agregam valores.

Entende-se que a $\mathrm{Web} 2.0$ viabilizou a construção do Ambiente Virtual Colaborativo, que corresponde a um espaço restrito das VCoPs, semelhante as intranets corporativas, com recursos tecnológicos de Realidade Virtual, de publicação e de comunicação dos conteúdos. No entanto, os portais de websites são espaços mais abertos com possibilidade de formação de VCoPs, sendo que os recursos tecnológicos estão voltados para a publicação e comunicação dos conteúdos. Os estudos de aplicações de $\mathrm{Web}$ 2.0 favorecem a colaboração e por conseguinte, disponibiliza formas de comunicação mediadas para motivar e sustentar os processos estruturantes das VCoPs nos Ambientes Virtuais Colaborativos. Como resultado do levantamento dos estudos das aplicações de Web 2.0 disponíveis na Internet apresentam-se as principais formas de comunicação mediadas para as VCoPs, proporcionados pelas dimensões do conhecimento e da comunicação que estão em permanente inter-relação conceitual para atualização do Ambiente Virtual Colaborativo constituído pelo paradigma tecnológico.

\subsection{Colaboração na Web 2.0}

Para Kvan (2000) o ato de colaboração reside nas atividades que são realizadas e que podem variar de intenção e graus de participação. Significa trabalhar com outras pessoas com objetivos comuns para buscar soluções coletivas de problemas que satisfaçam a todos os interessados. Para o autor o processo colaborativo é episódico e cíclico, isso quer dizer que os participantes trabalham em conjunto em determinados momentos, em seguida, dividem-se e seguem caminhos separados. Straus [2002] refere-se ao termo colaboração como o processo de planejar, resolver problemas e tomar decisões, empregado pelas pessoas que trabalham juntas em grupo, organização ou comunidades. Tapscott e William [2007] definem quatro tipos de colaboração: Peering - produção de bens e serviços que utiliza a força da colaboração em massa; Ideágoras utilização de mercados globais para achar mentes singularmente qualificadas para descobrir e desenvolver novos produtos e serviços; Prosumers - modelo no qual os clientes participam da criação de produtos de maneira ativa e contínua); e Novos Alexandrinos armazenamento de infinitas publicações científicas de acesso aberto.

Para Spyer [2007] a Web 2.0 fornece aplicativos de baixo custo de desenvolvimento para os websites, nos quais o conteúdo surge a partir do relacionamento dos participantes. Soluções e conteúdos de mais de um website podem ser combinados para produzir um resultado integrado. Sendo que o aspecto humano da $\mathrm{Web}$ 2.0 favoreceu a expansão de uma cultura de colaboração. O'Reilly [2007] destaca que os novos desenvolvimentos na $\mathrm{Web} 2.0$ têm facilitado a formação de uma Prática colaborativa entre os agentes, em uma arquitetura de participação, ou seja, uma estrutura reticular que suporta a Web é aumentada na medida em que maioria das pessoas usam. Essa arquitetura é construída em torno de pessoas e não das tecnologias para assim, colaborarem efetivamente para a disponibilização de serviços virtuais e organização dos conteúdos. 
$16^{\circ}$ Ergodesign - Congresso Internacional de Ergonomia e Usabilidade de Interfaces Humano Tecnológica: Produto, Informações Ambientes Construídos e Transporte

$16^{\circ}$ USIHC - Congresso Internacional de Ergonomia e Usabilidade de Interfaces Humano Computador

CINAHPA | 2017 - Congresso Internacional de Ambientes Hipermídia para Aprendizagem.

Resume-se então o termo colaboração como uma atividade que reúne sinergias e está baseada na interação pessoal, se manifesta num processo contínuo de mudança para criar e manter uma concepção compartilhada para a solução de um problema. $\mathrm{O}$ conteúdo dos ambientes virtuais também sofreu impacto com a Web 2.0, dando aos agentes a possibilidade de participar, de gerar e organizar as informações.

\subsection{Comunicação na Web 2.0}

As formas de comunicação oferecem recursos e tarefas diferentes, pois a seleção das formas de comunicação desempenha um papel essencial na colaboração entre as VCoPs. O ambiente virtual é o suporte para um novo pensamento comunicacional capaz de promover a aprendizagem colaborativa. O desafio é encontrar adequadas formas de comunicação para tornar explícito, acessível e compartilhado o conhecimento, estabelecendo a sua efetiva comunicação e por conseguinte, a prática colaborativa. Proporcionar a efetividade ao aspecto da formação, dimensão da comunicação e prática colaborativa do conhecimento, é uma questão importante e possível de se estabelecer por meio do Ambiente Virtual Colaborativo.

A Web 2.0 permite aprimorar a prática colaborativa das VCoPs, desde que a seleção das formas de comunicação provenientes e sustentadas por essas aplicações, estejam adequadas ao perfil dos participantes das VCoPs e aos seus conhecimentos compartilhados. As categorias de conhecimento, nesse estudo, que compõe as VCoPs estão direcionadas a cidades. Para considerar a colaboração de forma efetiva, destaca-se as formas de comunicação adequadas ao espaço urbano das cidades. Essas foram estabelecidas em torno das aplicações da $\mathrm{Web}$ 2.0 e do processo de criação de conhecimento [Nonaka e Takeuchi,1997; Choo, 2006]. A criação do conhecimento, segundo Chua et al, apresenta-se por meio dos processos de aquisição, disseminação, organização e compartilhamento, que respectivamente correspondem às formas de comunicação: aquisição- fóruns e wikis; disseminação- blogs e RSS; organização - Social tagging; e compartilhamento- redes sociais e multimídias, formalizado por meio da interface digital do Ambiente Virtual Colaborativo.

Um conjunto de critérios é necessário para identificar a qualidade das formas de comunicação para colaboração e distingui-las de formas de comunicação comuns, exemplificadas por Wenger et al [2005] como e-mail, telefones ou mensagens instantâneas, entendidas como formas de comunicação. As ferramentas tecnológicas para a colaboração comuns são apontadas pelos autores geralmente usadas para perguntas e respostas, não podem ser ampliadas em parte porque não permitem a reutilização de perguntas ou respostas. As VCoPs geralmente usam formas de comunicação como chats, fóruns de discussão, faqs, e-mail, mensagens instantâneas, whiteboard- quadro branco eletrônico, podcasting, videoconferência, assim como o uso das ferramentas de gestão e publicação, que estão disponíveis em websites pessoais, corporativos ou de relacionamento. $\mathrm{O}$ que difere o uso dessas ferramentas são os objetivos e o enfoque de seu uso, que possibilita aos membros das VCoPs o acesso e compartilhamento do conhecimento.

Conforme Carvalho [2013] as formas de comunicação reúnem sete aspectos pertinentes a indicação: 1.a interação que ocorre em um ambiente virtual gerando relações sociais e práticas colaborativas; 2 as metas nas quais os participantes das VCoPs necessitam alcançar de forma clara, transparente e que levem a compreensão das mesmas, e correspondam às necessidades de uma cultura, do perfil e das preferências dos participantes; 3 .as comunidades virtuais, aliado aos projetos que geram significado e que se faz presente nos diferentes papéis e cenários. As comunidades virtuais desenvolvem linguagens próprias como a hipertextual a partir das formas de comunicação como por exemplo, as Mensagens Instantâneas e 


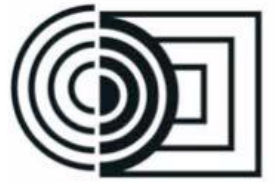

os Fóruns.

Assim como os 4.recursos tecnológicos, o domínio e a experiência dos participantes das VCoPs, utilizados para realizar tarefas e atividades; 5.o requisito tempo da realização das atividades, implica em custo e agilidade no fluxo de trabalho. Outro requisito a ser considerado é 6.o uso das formas de comunicação no foco das atividades, que dependem da participação específica e efetiva dos participantes da comunidade virtual. Sendo que o uso de conteúdos públicos e privados gerados pelas atividades podem ser recuperados com privacidade; 7.a usabilidade nas formas de comunicação permite o conforto na execução de atividades e a eficácia de resultados. Assim como a simplicidade no layout (linguagem e estilo) e uma relação "amigável" por meio da interface digital interativa trazem benefícios relativos ao acesso e conhecimento colaborativo compartilhado.

\subsection{Modelo de Crowdsourcing na Web 2.0}

Segundo Howe [2008] os indivíduos na Web 2.0 têm se reunido para executar tarefas, quase sempre mediante pouca ou nenhuma remuneração. Essa função que antes era somente dos empregados da organização, está se espalhando em vários setores como jornalismo, geografia e ciência. Este fenômeno no qual as soluções são geradas pelos participantes das comunidades virtuais, foi chamado pelo autor de crowdsourcing-construção coletiva. O termo crowdsourcing é usado por Tapscott e Willians [2007], para designar um modelo de produção e resolução de problemas online e distribuído que utiliza a inteligência e o conhecimento coletivo de voluntários, amadores ou não, para desenvolver novas tecnologias ou solucionar problemas.

$\mathrm{Na}$ Internet o conhecimento coletivo é designado de inteligência coletiva por Lévy [2003]. É uma inteligência que está em toda parte, é constantemente valorizada, coordenada e $16^{\circ}$ Ergodesign - Congresso Internacional de Ergonomia e Usabilidade de Interfaces Humano Tecnológica: Produto, Informações Ambientes Construídos e Transporte

$16^{\circ}$ USIHC - Congresso Internacional de Ergonomia e Usabilidade de Interfaces Humano Computador

CINAHPA | 2017 - Congresso Internacional de Ambientes Hipermídia para Aprendizagem. mobilizada em tempo real. O objetivo da inteligência coletiva é o reconhecimento e o enriquecimento mútuo dos indivíduos obtidos através de relações humanas baseadas em troca de saberes portanto, no compartilhamento do conhecimento. O crowdsourcing se utiliza da inteligência coletiva, ou seja, dos conhecimentos da comunidade para promover o engajamento da sociedade no processo de construção do projeto de políticas públicas para o desenvolvimento urbano sustentável, desde a identificação e priorização de problemas a seleção e desenvolvimento das soluções urbanas inovadoras pelos agentes urbanos.

Spyer [2007] cita algumas vantagens oferecidas pelos ambientes virtuais para a colaboração na forma de compartilhamento de conhecimentos: 1. Redução do custo de produção e disseminação - para quem está conectado, o esforço para disseminação de uma informação é bastante resumido. Por exemplo, para enviar uma mensagem de protesto basta repassar o conteúdo para os endereços de e-mail conhecidos; 2.

Redução no esforço de coordenação - fica mais fácil encontrar-se com pessoas de mesmo interesse, pois não depende das limitações de tempo e espaço; 3 . Ampliação do benefício - o bem online nunca será escasso, ou seja, um arquivo poderá ser copiado e distribuído infinitas vezes. Pode-se então afirmar que a evolução das aplicações da Web 2.0 está nas camadas de integração de serviços, de gestão e entre poderes; participação nas decisões; comunicação de múltiplas vias e colaboração na disponibilização de formas de comunicação adequadas para formação de VCoPs, utilizando para isso a crowdsourcing.

Cita-se como exemplo o Smart Mob mobilizantes inteligentes, um conceito criado por Rheingold [2007] e designa um grupo que se comporta de maneira inteligente e que faz parte de uma Rede cujas conexões crescem exponencialmente. Essa Rede permite que as pessoas se conectem a informações e a outras 
$16^{\circ}$ Ergodesign - Congresso Internacional de Ergonomia e Usabilidade de Interfaces Humano Tecnológica: Produto, Informações Ambientes Construídos e Transporte

$16^{\circ}$ USIHC - Congresso Internacional de Ergonomia e Usabilidade de Interfaces Humano Computador

CINAHPA | 2017 - Congresso Internacional de Ambientes Hipermídia para Aprendizagem.

pessoas, possibilitando assim uma coordenação social. Outro exemplo é OpenStreetMap é um projeto colaborativo do mapa do mundo, aberto e editável, inspirado em sites como a Wikipédia. Criado e mantido por diferentes comunidades de todo o planeta, por meio de uma estrutura democrática e transparente.

Haddad [2014] relacionou alguns exemplos de algumas iniciativas de negócios, projetos e movimentos que possuem lógica da Web $2.0 \mathrm{em}$ relação a colaboração para solucionar problemas do sistema urbano, criando produtos e serviços tais como: Mobilidade - Waze, Moovit, Uber, Getaround, Spinlister, Nimber, Turismo Vayable, Educação - Skillshare, Beved, Nós.vc, Meio Trabalho e Lazer - Laboriosa89, Catete92, entre outros. Pode-se dizer que a sociedade convive com os modelos horizontais de relacionamento, os quais propiciam fluxos de informação multidirecionais na promoção do engajamento e produção de conhecimento na melhoria do modo de vida urbano.

\section{Conclusão}

O modo de vida das comunidades humanas que convivem em regiões territoriais- neste caso cidades- compartilham interesses em comum. Para isso a comunicação colaborativa na composição do crowndsourcing prevê a criação de novas formas de ação e interação, portanto novos modos de vida urbana. Pode-se dizer que a visualização das informações, nas quais os agentes urbanos possam perceber um significado relevante, é encontrado por meio do modelo crowdsourcing, portanto, da inovação aberta e aplicações da Web 2.0. Verifica-se que tal procedimento adotado pelo crowdsourcing, onde os processos tecnológicos promovem e geram a co-criação de conhecimentos, agrega valor ao que é publicado pelo Governo, instituições e empresas. Proporcionar a efetividade ao aspecto da formação de comunidades, dimensão da comunicação e prática colaborativa do conhecimento é uma questão importante e possível de se estabelecer por meio dos
Ambientes Virtuais Colaborativos. A contribuição desta investigação busca articular informações e compartilhar o conhecimento entre as VCoPs das cidades, e gerar soluções urbanas em uma abordagem social, a partir da combinação de dados de diferentes fontes de informação encontradas na $\mathrm{Web} 2.0$.

A comunicação colaborativa ainda representa um desafio, devido adequação das formas de comunicação mediadas a uma determinada comunidade, ambiente e conhecimento específicos. Evidencia-se a necessidade de estudos futuros da apresentação dos requisitos com base na revisão de literatura dos modelos teóricos de cidades; das aplicações de Web 2.0 e Web 3.0 no que se refere a geração de serviços baseados na organização e no uso mais inteligente do conhecimento disponível na Internet; e validação entre os agentes urbanos que compõe as VCoPs. Assim, como conceber uma Rede Cidade de Soluções Urbanas Inovadoras Sustentáveis visando o Ambiente Virtual Colaborativo. Esses como elemento central e facilitador de um conjunto de estratégias de promoção das soluções urbanas e desenvolvimento econômico e social no cenário do sistema urbano. A pesquisa está em fase inicial prevendo na constituição da Rede Cidade parcerias na proposição de metodologias aos estudos acerca da gestão urbana e inovação social.

\section{BIBLIOGRAFIA}

ANTHONY, J. et al. Communities of practice: the source of competitive advantage in organisations. Journal of Knowledge Management Practice v. 10, n. 1, pp 1-7, 2009

BALLONI, A.; TARGOWSKI, A. Challenges And Reflections On Information, Knowledge, And Wisdom Societies \& Sociotechnical Systems. Saint Louis: ICIS- International Conference on Information Systems, 2010

BENFORD, S. et al Networked Virtual Reality 


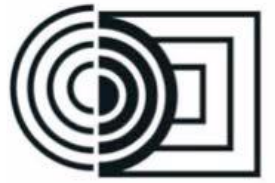

and Cooperative Work Presence:

Teleoperators and Virtual Environments, v. 4, n. 4, Massachusetts: MIT, 1995

CARAGLIU, A Smart cities in Europe. Eslováquia: 3rd Central European Conference in Regional Science, Košice - CERS, 2009

CARRILLO, F. Knowledge cities: approaches, experiences and perspectives. Burlington:

Elsevier, 2006

CARVALHO, M. Framework Conceitual para Ambiente Virtual Colaborativo das Comunidades Virtuais de Prática nas Universidades no Contexto de e-Gov. Tese de Doutorado em Engenharia e Gestão do Conhecimento, 2013

CHESBROUGH, H. Open Innovation: The New Imperative for Creating and Profiting from Technology. Harvard: Business School Press, 2003

CHOO, C. A organização do conhecimento São Paulo: Senac, 2003

CHUA, A.; GOH, D.; ANG, R. Web 2.0 applications in government web sites: Prevalence, use and correlations with perceived web site quality. England: Emerald Group Publishing Limited, Online Information Review, vol. 36 pp 175 - 195, 2012

COMISSÃO EUROPÉIA. Cidades de Amanhã Desafios, visões e perspectivas. Bruxelas, 2011

FLORIDA, R. The rise of creative class. New York: Basic Books, 2002 Cities and the creative class.

New York: Routledge, 2005

GARCÍA-RIVADULLA, S. Actitud 2.0: usos de la web social en las Bibliotecas universitarias. Uruguay, 2010

GOUVEIA, L. Ambientes Virtuais $16^{\circ}$ Ergodesign - Congresso Internacional de Ergonomia e Usabilidade de Interfaces Humano Tecnológica: Produto, Informações Ambientes Construídos e Transporte

$16^{\circ}$ USIHC - Congresso Internacional de Ergonomia e Usabilidade de Interfaces Humano Computador

CINAHPA | 2017 - Congresso Internacional de Ambientes Hipermídia para Aprendizagem.

Colaborativos: a procura de formas alternativas de interação. Porto: Revista Politécnica n. 2, 2000

GUIMARAENS, M. Estatuto da Cidade e Instrumentos de Política Urbana. Porto Alegre: Revista da Faculdade de Direito UniRitter v. 11, 2010

HALL, R. E. et al. The vision of a smart city In: Proceedings of the 2nd International Life Extension Technology Workshop. New York: Brookhaven National Lab, 2000

HOWE, J. The Rise of Crowdsourcing, Wired, 2006 O Poder das Multidões. Rio de Janeiro: Campus, 2008

KIRNER, C.; TORI, R. Realidade Virtual: Conceitos e Tendências. São Paulo: Livro do VII Symposium on Virtual Reality, 19.10. 2004. Disponível em:

http://www.ckirner.com/download/capitulos/livr o_pre_simp-2004.pdfl Acesso em: 10/03/2017

KOMNINOS, N. Intelligent cities: innovation, knowledge systems and digital spaces London: Spon Press, 2002

Intelligent Cities: The Encyclopedia of Digital Government. London: Idea Group Reference, pp.1100-1104, 2006

KUNZMANN, K. The strategic dimensions of knowledge industries in urban development. Germany: The Planning Review, 45(1), 40-47, 2009

KVAN, T. Collaborative design: what it is? Netherlands: Automation in construction, v.9, n. 4, p. 409-415, 2000

LAVE, J., WENGER, E. Communities of practice: learning, meaning and identity. Nova York: Cambridge University Press, 1998

LEIPZIG CHARTER ON SUSTAINABLE 


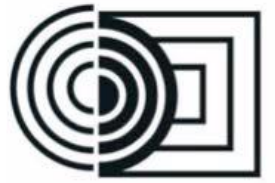

\section{EUROPEAN CITIES Leipzig: EU, 2007}

LÉVY, P. Pela ciberdemocracia. In: Moraes, D. Por uma outra comunicação pp. 367-384 Rio de Janeiro: Record, 2003

NONAKA, I; TAKEUCHI, H. Criação de conhecimento na empresa: como as empresas japonesas geram a dinâmica da inovação. Rio de Janeiro: Campus, 1997

O'REILLY, T. What Is Web 2.0: Design Patterns and Business Models for the Next Generation of Software Germany: International Journal of Digital Economics n. 65 pp. 17-37 march, 2007

PALLOFF, R.; PRATT, K. Building online learning communities: effective strategies for the virtual classroom. San Francisco:

JosseyBass, 2007

RHEINGOLD, H. Comunidades Virtuais. Hesselbein, F. et al. A Comunidade do Futuro: ideias para uma nova comunidade. São Paulo: Futura, 1998

RHEINGOLD, H. The New Interactivism: A Manifesto for the Information Age.

Washington: SpeakOut.com, 1999

Revolution, 2007

Smart Mobs: The Next Social

SAAD, B. Estratégias para a mídia digital: Internet, informação e comunicação. São Paulo: SENAC, 2003

SOUZA, C.; AWAD, J. Cidades sustentáveis, cidades inteligentes. Porto Alegre: Bookman, 2012

SPYER, J. Conectado: O que a internet faz com você e o que você pode fazer com ela. Rio de Janeiro: Jorge Zahar, 2007

STEVENTON, A.; WRIGHT, S. Intelligent spaces: the application of pervasive $16^{\circ}$ Ergodesign - Congresso Internacional de Ergonomia e Usabilidade de Interfaces Humano Tecnológica: Produto, Informações Ambientes Construídos e Transporte

$16^{\circ}$ USIHC - Congresso Internacional de Ergonomia e Usabilidade de Interfaces Humano Computador

CINAHPA | 2017 - Congresso Internacional de Ambientes Hipermídia para Aprendizagem.
ICT. London: Springer, 2009

STRAUS, D. How to make collaboration work: powerful ways to build consensus, solve problems, and make decisions. San Francisco: Berrett-Koehler Publishers, 2002

TAPSCOTT, D.; WILLIANS, A. Wikinomics: como a colaboração em massa pode mudar o seu negócio. Rio de Janeiro: Nova Fronteira, 2007

The Prosumers.

In: Wikinomics: how mass collaboration changes everything. New York: Penguin Books, capítulo 5, p. 124-150, 2007

\section{TERRA, J.; GORDON, C. Portais} colaborativos: a revolução na gestão do conhecimento. São Paulo: Negócio, 2002

TOPPETA, D. The Smart City vision: How Innovation and ICT can build smart, "liveable", sustainable cities. THINK! REPORT: The Innovation Knowledge Foundation, 2010

VALÉRIO, A. et al. Realidade Virtual: Definições, Dispositivos e Aplicações. São Paulo: USP, 2002

von WARTBURG, I. et al Knowledge Generation in Virtual Communities of Practice Academy of Management, Hawaii: August 5-10 ${ }^{\text {th }}$, Honolulu, 2005

WENGER, E; McDERMOTT, R; SNYDER, W. Cultivating Communities of practice: a guide to managing knowledge. Boston: Harvard Business School Press, 2002

WENGER, E., WHITE, N., SMITH, J.

Technology for Communities, 2005 Disponível em:http://pt.scribd.com/doc/2531741/Technolog y-forcommunities-Wenger-CEFRIO-BookChapter-v-5-2 Acesso em: 04/03/2017

WEXELBLAT, A. Virtual reality applications 


\section{$16^{\circ}$}

ERGODESIGN USIHC CINAHPA $16^{\circ}$ Ergodesign - Congresso Internacional de Ergonomia e Usabilidade de Interfaces Humano Tecnológica: Produto, Informações Ambientes Construídos e Transporte

$16^{\circ}$ USIHC - Congresso Internacional de Ergonomia e Usabilidade de Interfaces Humano Computador

CINAHPA | 2017 - Congresso Internacional de Ambientes Hipermídia para Aprendizagem.

and explorations. San Diego: Academic Press

Professional, Inc., 1993 